\title{
Breast cancer characteristics and HIV among 1,092 women in Soweto, South Africa
}

\author{
Herbert Cubasch $\cdot$ Maureen Joffe $\cdot$ Rachel Hanisch $\cdot$ Joachim Schuz $\cdot$ \\ Alfred I. Neugut $\cdot$ Alan Karstaedt $\cdot$ Nadine Broeze $\cdot$ Eunice van den Berg • \\ Valerie McCormack $\cdot$ Judith S. Jacobson
}

Received: 18 March 2013 / Accepted: 8 June 2013/Published online: 26 June 2013

(c) The Author(s) 2013. This article is published with open access at Springerlink.com

\begin{abstract}
In the low-income HIV-endemic regions of sub-Saharan Africa, malignancies related to HIV have long been recognized as a major public health problem. However, epithelial malignancies associated with older age, such as breast cancer, are also rising dramatically in those regions. We compared consecutive HIV-positive and -negative black women diagnosed with breast cancer at a large public hospital in Soweto, South Africa, on age, year of diagnosis, stage, grade, and receptor status, and grouped HIV-positive patients by CD4 cell counts. We computed prevalence ratios of the associations of HIV status and CD4 category with stage, grade, receptor status, and among the HIV-positive patients, receipt of ART, controlling for age and year of diagnosis. Of 1,092 patients, 765 were tested for HIV; $151(19.7 \%)$ tested positive, a prevalence similar to that in the source population. Although, HIV-positive patients were younger than HIV-negative patients $(p<0.001)$, HIV status was not associated with the tumor characteristics. Thirty-seven women $(25.9 \%)$ had CD4 cell counts $<200$ cells $/ \mu$ l. Patients in that severely immunocompromised group were
\end{abstract}

H. Cubasch · M. Joffe · A. Karstaedt · N. Broeze ·

E. van den Berg

University of the Witwatersrand, Johannesburg, South Africa

H. Cubasch · A. Karstaedt · N. Broeze

Chris Hani Baragwanath Academic Hospital, Johannesburg, South Africa

M. Joffe

Wits Health Consortium, Johannesburg, South Africa

R. Hanisch · J. Schuz · V. McCormack

Section of Environment and Radiation, International Agency

for Research on Cancer, Lyon 69008, France older than those in the other groups $(p=0.01)$. This study is the first to analyze the association of HIV with breast cancer in a large sample. Based on similar HIV prevalence in our sample and the population of the hospital's catchment area, clinicians serving HIV-endemic communities should promote routine HIV testing of younger breast cancer patients and immediate treatment of those who test positive, prior to the initiation of chemotherapy. Research is needed on treatment and outcomes given HIV and low CD4 cell count.

Keywords Breast cancer and HIV - South Africa . Breast cancer and race/ethnicity · HIV and cancer

\section{Introduction}

In recent years, breast cancer incidence and mortality rates in Africa have risen rapidly. Women diagnosed with breast cancer in the developing countries generally have a poorer prognosis than those in more developed countries [1]. 
Among women in sub-Saharan Africa, breast cancer has become the most common malignancy and cause of cancerrelated deaths. [2].

Sub-Saharan Africa also has almost $70 \%$ of the world's cases of human immunodeficiency virus (HIV) and acquired immunodeficiency (AIDS) cases; and HIV incidence rates are rising faster among women than among men [3]. HIV has always been associated with certain unusual cancers, especially Kaposi's sarcoma and non-Hodgkin lymphomas, as well as cervical cancer [46]. However, due to the success of anti-retroviral treatment (ART), HIV is changing from a major cause of death among young adults and children to a chronic condition with which the patients may survive into middle age and beyond. That change raises concerns about how HIV and its treatment may affect the risks, characteristics, treatment, and outcomes of the common epithelial cancers of middle- and older-aged adults, such as breast cancer [7, 8].

A few population-based cancer registry-linked studies have been conducted on HIV and breast cancer. Most have found breast cancer incidence rates either no higher or slightly lower among HIV-positive women than among HIV-negative women or women in the general population [8-12]. A study conducted in 1995-1999 in Johannesburg, South Africa, found that 43/687 black women with breast cancer $(6.3 \%)$ and a similar proportion of controls were HIV-positive [4]. It has even been suggested that HIV may reduce the risk of breast cancer [13]. Postulated mechanisms include HIV-induced impaired proliferation of breast cells, and breast cancer cell apoptosis induced by binding of HIV to specific receptors [13-15]. However, solid evidence that HIV affects breast cancer risk for good or ill is lacking. In addition, very little is known about the association of HIV status with breast tumor subtypes, stage at diagnosis, and tumor grade, especially among the most severely immunocompromised HIVinfected women, those whose CD4 cell counts are less than 200 cells/ $\mu$ l. To determine whether and how HIV status may be relevant to treatment decision making, studies are needed in HIV-endemic countries, where HIV-positive breast cancer patients are most likely to be found.

South Africa is a country in transition, with an ethnically diverse population and features of both developing and industrialized countries. Although, much of its population is very poor, South Africa has several public tertiary care hospitals with facilities that are comparable to those in the industrialized world. Here, we report on the demographic and clinical characteristics of HIV-positive and -negative black women diagnosed with breast cancer in Soweto, South Africa, in 2006-2012.

\section{Methods}

Setting and patients

Chris Hani Baragwanath Academic Hospital (CHBAH), one of the largest hospitals in the world, is a public tertiary care institution that serves the largely black and lowincome community of greater Soweto, in the southwestern part of Johannesburg, South Africa, and neighboring periurban communities, which are home to nearly 3 million people. From the late 1950s to the mid-1970s, only about 20 new cases of breast cancer were diagnosed per year at CHBAH (Professor Charles Isaacson, personal communication). Currently, the hospital's Batho Pele Breast Unit, a member of the International Breast Centres Network, receives 400-500 patient visits and diagnoses up to 25 new breast cancers per month. The vast majority of patients have never undergone mammographic screening for breast cancer and are symptomatic at diagnosis. Patients receive standard diagnostics and multimodality treatment with surgery, chemotherapy, radiotherapy, and hormonal treatment in keeping with international guidelines. Decision making is monitored by a multidisciplinary team of surgeons, medical oncologists, radiation oncologists, and palliative care physicians.

In 2006, we developed an electronic database of all the patients seen with a diagnosis of breast cancer. As of July 2012, the database included 1,228 patients with invasive breast carcinoma. For the current analysis, we excluded 12 male patients and 124 nonblack (49 white, 46 colored, 22 Asian, and 7 missing ethnicity data) female patients, and included all black female patients diagnosed with histologically confirmed breast cancer from October 2006 through July 2012. The study was approved by the Wits Human Research Ethics Committee (Medical).

\section{Receptor status}

As part of the diagnostic workup, estrogen receptor (ER), progesterone receptor (PR), and HER2 status were measured by the National Health Laboratory Service (NHLS) of South Africa (www.nhls.ac.za). Hematoxylin and eosinophil (H\&E) staining of $3-\mu \mathrm{m}$ tissue sections was verified for sufficient numbers of invasive cells and fixation quality. The fully automated immunostainer Ventana Benchmark XT was used for measurement of ER and PR levels by SP1 rabbit monoclonal CONFIRM ${ }^{\mathrm{TM}}$ anti-ER $1 \mathrm{Ab}$. Tumors with $<1 \%$ ER or PR nuclei staining were considered negative; tumors with weak (1-10\%), moderate $(10-33 \%)$, or strong ( $>33 \%$ ) staining were considered positive. HER2 was analyzed using Ventana 4B5 rabbit monoclonal PATHWAY ${ }^{\circledR}$ anti-HER2/neu $1^{\circ} \mathrm{Ab}$. Tumors 
with no, weak, or moderate staining (scores $0,1+, 2+$ ) were classified as HER2-negative, and those with staining intensity $3+$ as positive [16-18].

\section{HIV testing}

The prevalence of HIV is high in Soweto ( $\sim 40 \%$ among women in their thirties). Because most patients seen in the breast clinic have never been tested and are likely to need chemotherapy, all were offered HIV testing during their diagnostic workup. HIV-1 and -2 antibodies were detected from patients' blood samples using either a fourth generation ELISA (Elecsys and Cobas 602, Roche diagnostics, Mannheim, Germany) or a rapid HIV1/2 kit (Determine, Alere Medical Co., Japan). If a positive test was obtained by either method, a confirmatory test was performed using a fourth generation ELISA (Abbott Architect, Wiesbaden, Germany). Among HIV-positive patients, we calculated CD4 cell counts per microliter of blood (cells $/ \mu \mathrm{l})$, by means of a dual-platform, panleucogating technique, using total leukocytes as the common denominator. Cell counts were determined using the Beckmann-Coulter Flow $\mathrm{CARE}^{\mathrm{TM}} 500$ Analyzer (Becton-Dickinson Biosciences, San Jose, CA, USA) [19]. Women who tested HIV-positive were referred to the specialist HIV unit so that they could begin ART prior to initiating treatment for their cancer.

\section{Statistical analysis}

We categorized the patients as HIV-positive, HIV-negative, or HIV status unknown. We then compared distributions among categories of demographic and clinical characteristics of the HIV- positive and HIV-negative groups, using Chi square tests of the statistical significance of group differences. In addition, we categorized the HIVpositive patients by CD4 cell count categories: $\geq 500$, 200-499, and $<200$ cells/ $\eta 1$, and compared the distributions of demographic and clinical characteristics of those groups, using Chi square tests or, where necessary, Fisher exact tests of statistical significance. Differences in CD4 count distributions by breast tumor characteristics were also analysed using the nonparametric Kruskal-Wallis test.

Because in this case series, the characteristics of interest were relatively common, we used prevalence ratios (PR) as measures of association [20, 21]. We developed generalized linear models for binary outcomes with robust variance and a log link function to evaluate the associations of dichotomized stage at diagnosis (stages III and IV vs stages I and II), tumor grade (grades 2 and 3 vs grade 1), and ER, PR, HER2, and triple-negative (ER-, PR-, and HER2-) receptor status (positive vs negative) with HIV status (positive vs negative and unknown vs negative), controlling for age and year of diagnosis (continuous). Finally, among HIV-positive women, the associations of CD4 cell count categories with tumor characteristics and prior ART treatment were also evaluated. All the regression models included age at and year of diagnosis.

We also compared the percentages of breast cancer patients who were HIV-positive to those in the general population within age strata. We obtained population agespecific HIV prevalence estimates (\%) from the 2008-2010 national antenatal-sentinel HIV prevalence surveys for Gauteng Province (http://www.doh.gov.za/docs/reports/ 2011/hiv_aids_survey.pdf) for women younger than 45 years, and from the Soweto Women's Study, a crosssectional study of 500 women aged 45 years and older, conducted in July 2009 (http://www.anovahealth.co.za/ images/uploads/Mental\%20Health\%20Symposium $\% 20$ pre sentation \%20-\%20Cape\%20Town, \%20August $\% 202011 \%$ 2010.pdf) for older women. Expected proportions of HIVpositive women in each 5-year age category were compared with observed numbers using the Chi squared test, and age-adjusted risk ratios of the association of HIV with breast cancer were calculated. Among our patients, missingness of data on HIV status was strongly associated with age, and age had a strong inverse association with HIVpositive status. We, therefore, used multiple imputation to estimate the HIV-positive percentage of all breast cancer patients, based on a logistic regression model for the association of HIV with age (in pentads), stage, and ER, PR, and HER2 status.

\section{Results}

The CHBAH database included 1,092 black women who were diagnosed with invasive breast carcinoma during the 6-year study period. Of the 765 (70\% of 1,092), whose HIV status was known, 151 (19.7\% of those tested) were HIV-positive.

From 2006-2007 to 2010-2012, the proportion of patients who were tested for HIV increased from 43 to $77 \%$, but among those tested, the proportion of positives declined from 29 to $18 \%$. Among those tested for HIV, $35.2 \%$ of patients under age 50 years, $12.1 \%$ of patients aged 50-59 years, and $4 \%$ of patients aged over 60 years were HIV-positive (Table 1).

HIV status in relation to breast cancer characteristics at diagnosis

More than $50 \%$ of the patients were diagnosed in stage III (A-C) or stage IV, and fewer than $10 \%$ were diagnosed with tumors of grade 1; but in bivariate analysis, neither the stage nor the tumor grade at diagnosis was associated with HIV status. Among the patients for whom data were available on molecular subtype, 614/966 (63.6\%) had 
Table 1 Demographic and clinical characteristics of black women diagnosed with breast cancer at Chris Hani Baragwanath Academic Hospital, South Africa, 2006-2012, by HIV status

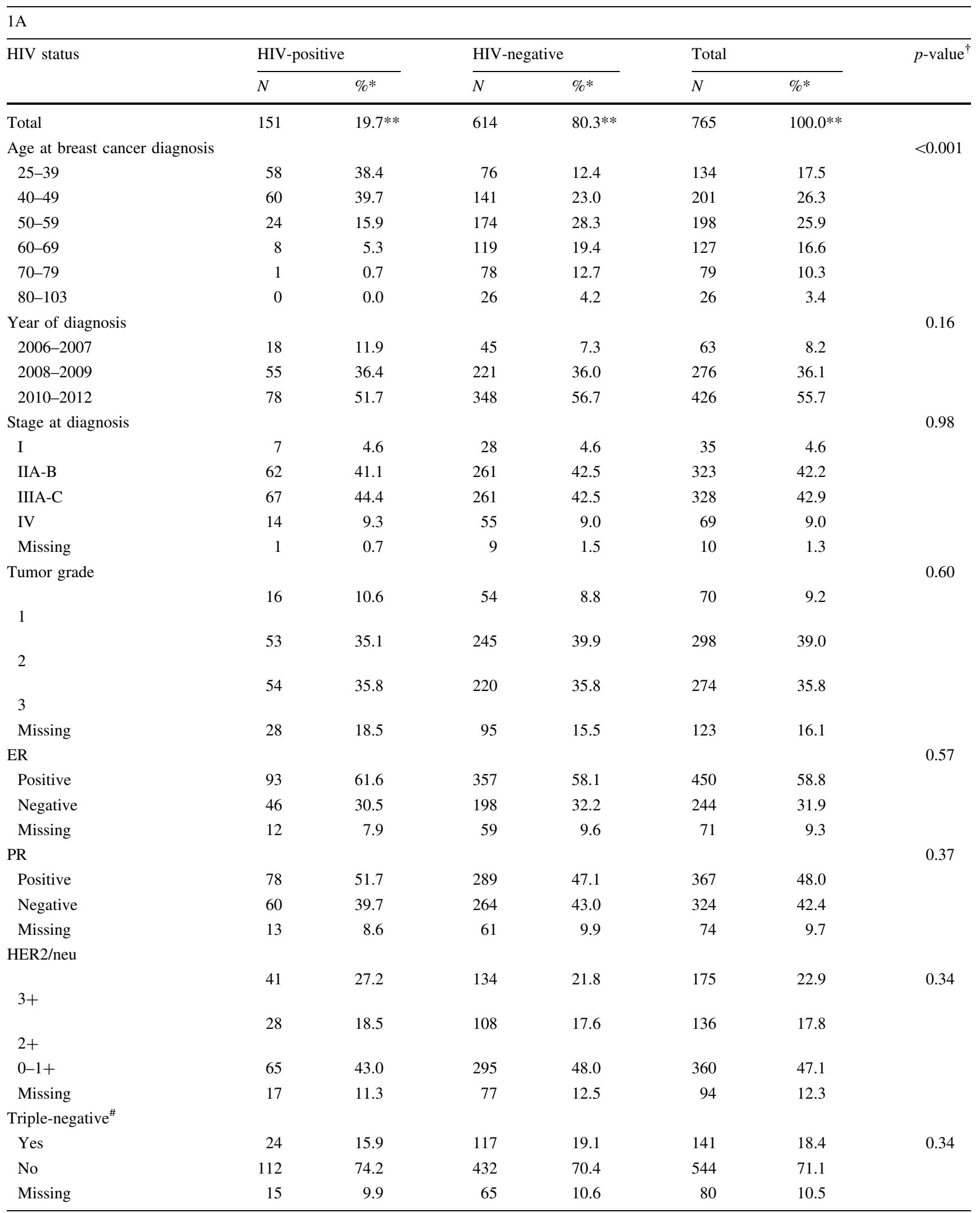


Table 1 continued

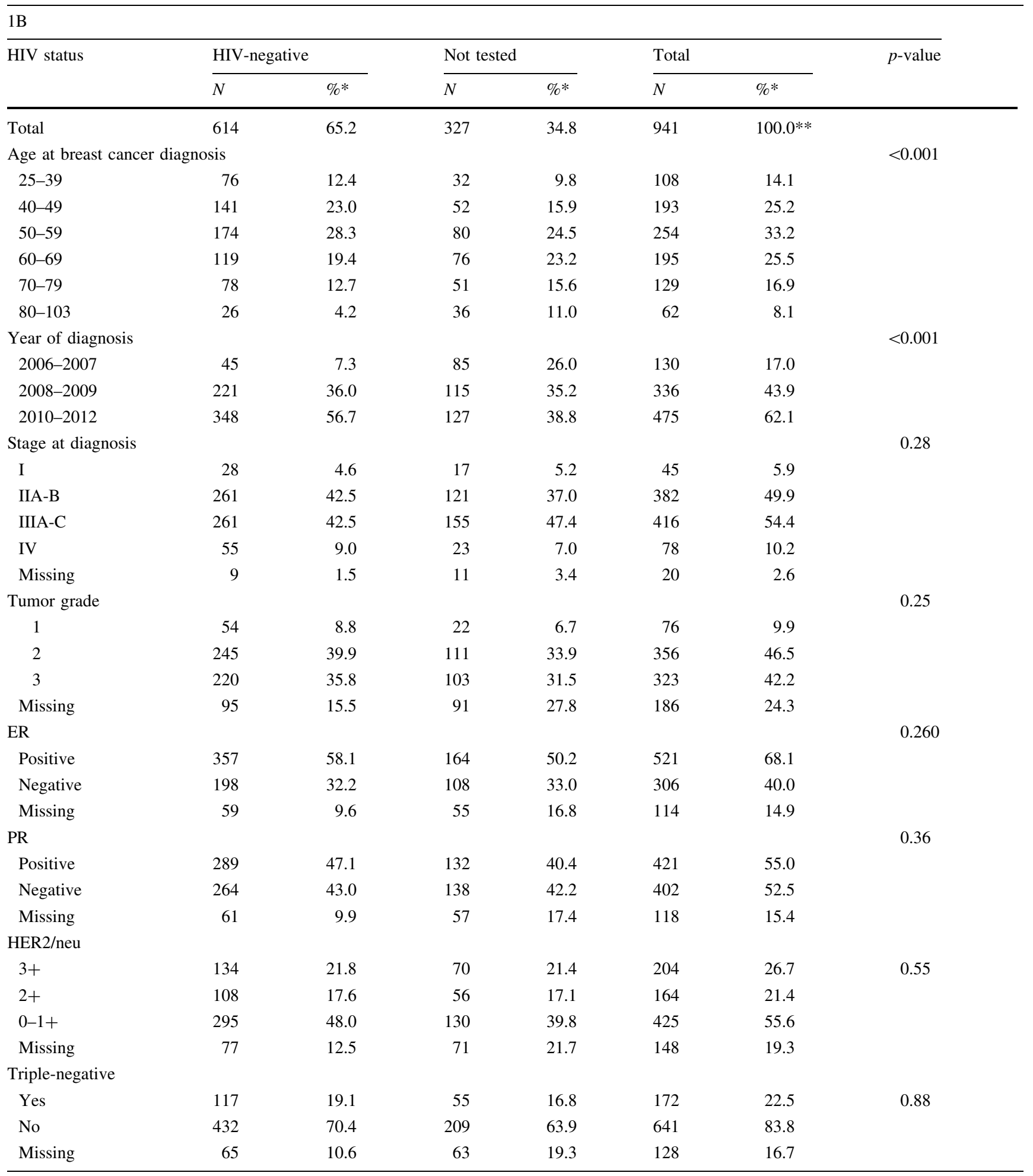

* Column percents

** Row percents

\# Triple-negative is defined as ER-, PR-, and HER2/neu-negative (HER2 negative includes scores 0-2+)

$\dagger$ Chi square tests for differences in non-missing proportions between HIV+ and HIV- patients 
ER-positive, 499/961 (51.9\%) with PR-positive, and 245/927 (26.4\%) with HER2-positive breast tumors. A total of 196/949 (20.7\%) women were classified as having triple-negative breast cancer. In univariate analysis, molecular subtype was not associated with HIV status (Table 1). In models that included age at and year of diagnosis, HIV status was also not associated with stages III or IV vs stages I and II; grades 2 and 3 vs grade 1; or molecular subtypes (Table 2).

Among HIV-positive women, the median CD4 count was 316 cells/ $\mu \mathrm{l}$ (range 7-1,203, interquartile range 196-487). Using clinical cutpoints, 34 (23.8\%) were classified as having a CD4 cell count of $\geq 500$ cells $/ \mu$ l or higher, 72 (50.4\%) had CD4 cell counts between 200 and 499, and 37 (25.9\%) had CD4 cell counts of 200 cells/ $\mu 1$ or below, indicative of severe immunosuppression. The patients in that group were older than the other HIVpositive patients $(p=0.01)$ and had marginally higher stages of breast cancer $(p=0.05)$, but did not differ from them in other respects (Table 3 ). With age and year of diagnosis taken into account, CD4 cell counts were not associated with stage at diagnosis; tumor grade; ER, PR, HER2, or triple-negative receptor status; or receipt of ART (Table 4). Adjustment for receipt of ART scarcely changed the point estimates.

HIV prevalence in breast cancer patients compared to the general population

Because HIV status was so strongly associated with age, we compared the prevalence of HIV among patients in our database and women in the source population (Soweto/ Gauteng Province) within age pentads (Fig. 1). Except in

Table 2 Associations of breast cancer stage, grade, and molecular subtype with HIV status, controlling for age at and year of diagnosis

\begin{tabular}{|c|c|c|c|c|}
\hline & \multicolumn{2}{|c|}{$\begin{array}{l}\text { HIV-positive vs } \\
\text { HIV-negative }\end{array}$} & \multicolumn{2}{|c|}{$\begin{array}{l}\text { HIV status } \\
\text { unknown vs } \\
\text { HIV-negative }\end{array}$} \\
\hline & $\mathrm{PR}^{*}$ & $95 \% \mathrm{CI}$ & $\mathrm{PR}^{*}$ & $95 \% \mathrm{CI}$ \\
\hline Stage III vs stages I and II & 1.08 & $0.89-1.32$ & 1.00 & $1.00-1.01$ \\
\hline Stage IV vs stages I and II & 1.04 & $0.60-1.82$ & 0.82 & $0.51-1.30$ \\
\hline Grade 2 vs grade 1 & 0.88 & $0.76-1.01$ & 1.05 & $0.96-1.15$ \\
\hline Grade 3 vs grade 1 & 0.87 & $0.76-1.01$ & 1.03 & $0.93-1.14$ \\
\hline ER-positive vs ER-negative & 1.06 & $0.92-1.23$ & 0.98 & $0.87-1.10$ \\
\hline PR-positive vs PR-negative & 1.13 & $0.95-1.35$ & 0.98 & $0.84-1.14$ \\
\hline $\begin{array}{l}\text { HER2-positive vs HER2- } \\
\text { negative }\end{array}$ & 1.07 & $0.78-1.46$ & 1.08 & $0.83-1.40$ \\
\hline Triple-negative vs other & 0.84 & $0.55-1.27$ & 0.94 & $0.70-1.27$ \\
\hline
\end{tabular}

* Prevalence ratios the 40-44 years age group, the $95 \%$ confidence intervals for HIV prevalence among the breast cancer patients included the population proportion. In a model that controlled for age (in pentads), HIV prevalence among our patients did not differ from that in the source population (RR 1.20, $p=0.13$ ).

The $151 \mathrm{HIV}$-positive patients represented $19.7 \%$ of the 765 tested women, but only $13.8 \%$ of the total sample of 1,092 breast cancer patients because the 327 untested women were older on the average than the tested women. After HIV status was imputed for women with unknown status, taking age, stage, and ER, PR, and HER2 status into account, the estimated HIV prevalence among all 1,092 breast cancer patients was $18.1 \%$.

\section{Discussion}

This study may be the first to evaluate the association of HIV with prognostic factors in a sample of more than 1,000 black breast cancer patients from an African population with high HIV prevalence. Nearly $20 \%$ of the patients were HIV-positive, a proportion and age distribution similar to those of the female population of the Soweto area. Only age at diagnosis was associated with HIV status, and that association was fully explained by the age distribution of HIV in the source population. Onethird of patients under age 50 years were HIV-positive. Those findings highlight the need for HIV testing of breast cancer patients, especially young patients, in HIVendemic populations.

In Johannesburg in 1995-1999, HIV prevalence among both breast cancer patients and controls was $6.3 \%$ [4]. A decade or so later, the prevalence of HIV among both breast cancer patients and the Soweto population was roughly three times higher. If that pattern applies to other HIV-endemic populations, a substantial proportion of breast cancer patients, especially young ones, may be HIVpositive, and HIV status, or at least CD4 cell count, may become an important consideration in breast cancer treatment.

Studies are needed to assess the association of HIV status with access to cancer diagnostic and treatment facilities; adherence to treatment, support or the lack of it for dual-diagnosis patients by families, communities, and health care providers, especially given the special challenges of HIV and cancer treatment. Studies are needed to determine whether cancer treatment interacts with HIV status and treatment, and how HIV status affects survival with cancer, especially among young patients. Our null findings regarding stage, grade, and molecular subtype suggest that HIV does not affect survival, but they require confirmation from follow-up studies. 
Table 3 Demographic and clinical characteristics of HIV-positive breast cancer patients by CD4 count

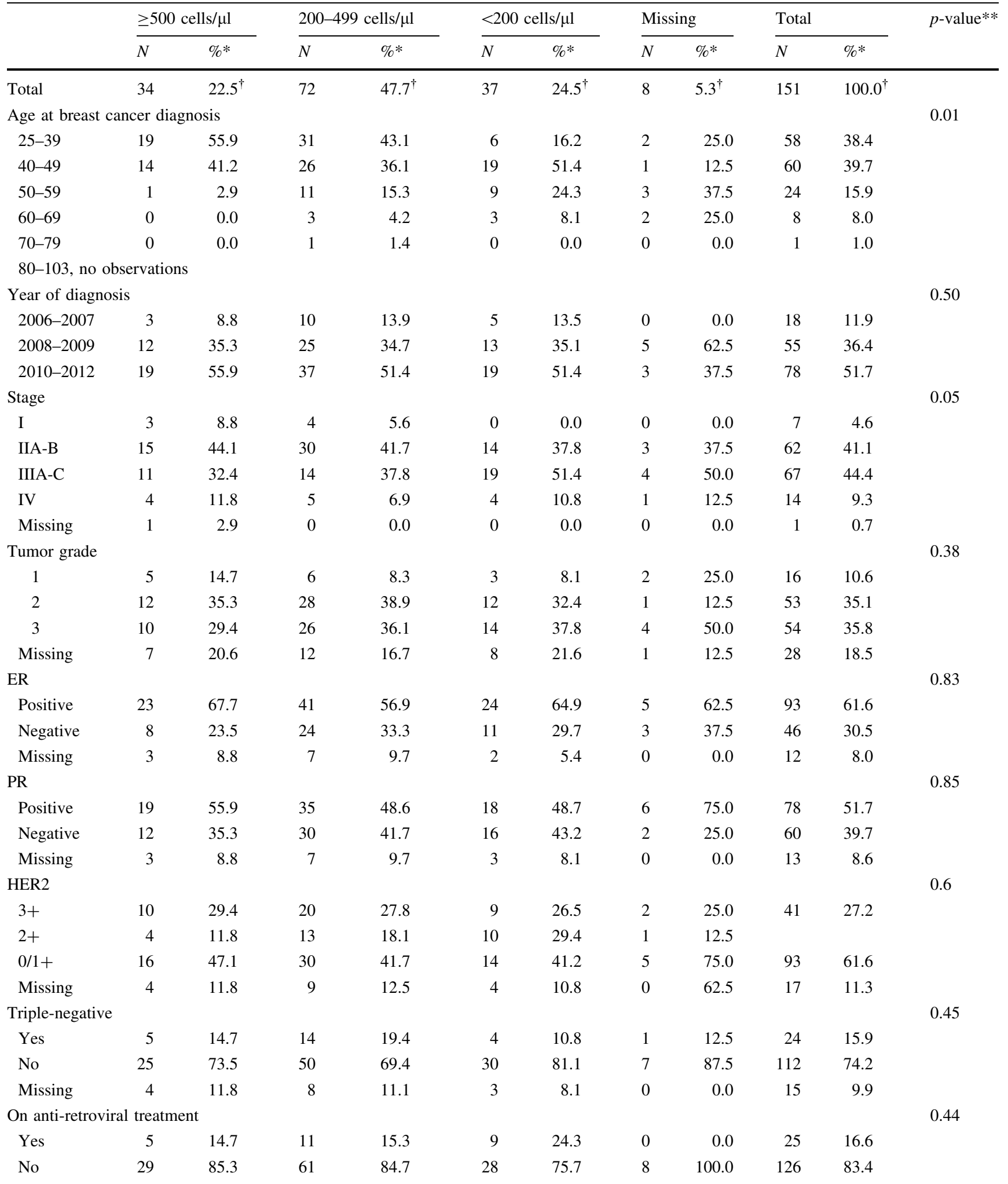

* Column percents

** Non-parametric Kruskal-Wallis test for differences in non-missing proportions by CD4 cell count group

$\dagger$ Row percents 
Table 4 Associations of breast cancer stage, grade, and molecular subtype with CD4 cell counts and treatment status of HIV-positive breast cancer patients, controlling for age at and year of diagnosis

\begin{tabular}{|c|c|c|c|c|}
\hline & \multicolumn{2}{|c|}{$200-499$ cells $/ \eta 1(v s \geq 500$ cells $/ \mu 1)$} & \multicolumn{2}{|c|}{$<200$ cells $/ \eta 1(v s \geq 500$ cells $/ \mu \mathrm{l})$} \\
\hline & $\mathrm{PR}^{*}$ & $95 \% \mathrm{CI}$ & $\mathrm{PR}^{*}$ & $95 \% \mathrm{CI}$ \\
\hline Stage III vs stages I and II & 1.18 & $0.68-2.03$ & 1.30 & $0.73-2.34$ \\
\hline Stage IV vs stages I and II & 0.64 & $0.19-2.14$ & 1.00 & $0.26-3.94$ \\
\hline Grade 2 vs grade 1 & 1.18 & $0.84-1.66$ & 1.13 & $0.74-1.72$ \\
\hline Grade 3 vs grade 1 & 1.29 & $0.88-1.90$ & 1.32 & $0.86-2.02$ \\
\hline ER-positive vs ER-negative & 0.88 & $0.66-1.18$ & 0.94 & $0.68-1.31$ \\
\hline PR-positive vs PR-negative & 0.88 & $0.61-1.28$ & 0.86 & $0.55-1.35$ \\
\hline HER2-positive vs HER2-negative & 0.97 & $0.51-1.82$ & 0.80 & $0.35-1.83$ \\
\hline Triple-negative vs other & 0.97 & $0.51-1.82$ & 0.80 & $0.35-1.83$ \\
\hline On anti-retroviral therapy & 1.06 & $0.41-2.74$ & 1.93 & $0.71-5.22$ \\
\hline
\end{tabular}

* Prevalence ratios

Fig. 1 Age-stratified HIV prevalence $(\%)$ in breast cancer patients diagnosed at the Chris Hani Baragwanath Academic Hospital (2006-2011) and in women from the Gauteng general population

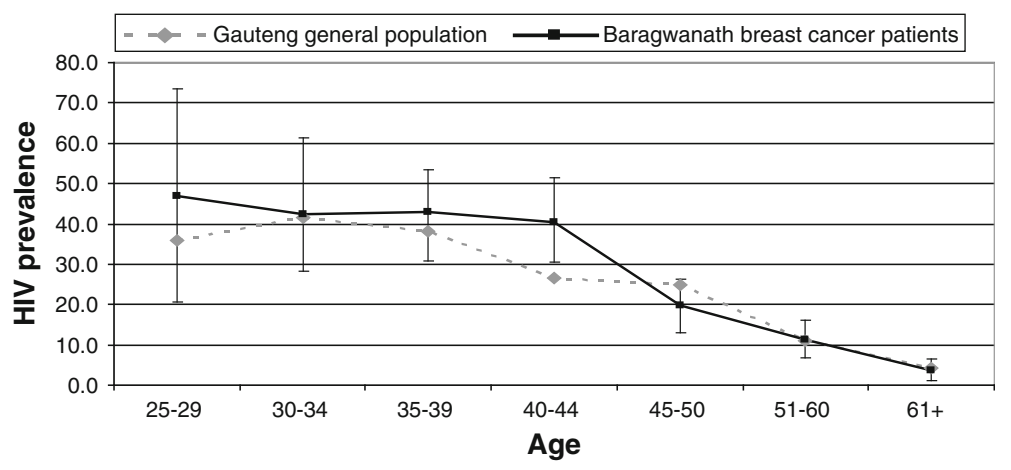

The similarity in HIV prevalence between breast cancer patients and the Soweto population suggests that HIV may not be related to breast cancer risk [13]. However, we did not attempt to evaluate HIV as a risk factor for breast cancer because we were unable to adjust for potentially confounding factors, such as parity, age at first birth, and body mass index, which are associated with both HIV and breast cancer [22].

We found no association of HIV with stage at diagnosis. In the future, if the facilities that provide care for HIVpositive individuals educate patients about breast cancer, or provide clinical breast examinations as part of their routine care, HIV-positive women may be more likely to be diagnosed with breast cancer at early stages than other women. However, until now, those facilities have found it difficult to provide even cervical screening, the need for which is much more widely accepted in the setting of HIV. In those respects, the HIV clinics do not differ much from the primary care clinics, which provide breast examination only on request at best.

A recent investigation has suggested that anti-HIV medication may affect breast cancer risk either by inhibiting a hypothesized preventive effect of HIV on breast cancer or by causing breast cancer cell apoptosis [23]. We found no association of breast cancer prognostic factors with ART among HIV-positive patients, but only 25 of the 151 patients, including 9 of the 37 severely immunocompromised patients, were receiving ART.

CD4 cell count was associated with age; only one of 34 patients in the high CD4 cell count group was older than 50 (2.9\%), compared with 15 of the 72 in the middle group (20.9\%), and 12 of the 37 severely immunocompromised (32.4\%). The association of age with low CD4 cell count may reflect longer duration of HIV infection.

The treatment of cancer patients with very low CD4 counts presents special problems. Most of the 37 HIVpositive patients with very low counts $(62.2 \%)$ were diagnosed in stage III or IV, compared to $32.1 \%$ of other HIV-positive patients $(p=0.003)$. Patients with late stage cancers usually receive aggressive chemotherapy, but without ART cover such treatment may be rapidly fatal for patients with low CD4 cell counts. Giving ART and waiting for the CD4 cell count to rise before providing chemotherapy is also risky. We believe that the safest approach is to initiate chemotherapy after initiating ART. Modifications of standard regimens for patients with the 
two diagnoses have been proposed, but evidence for the safety or efficacy of such modifications, compared to alternatives, is lacking [24, 25]. Clinical studies are needed to address this issue, but they are unlikely to be undertaken in the near future.

A limitation of our study is that nearly $30 \%$ of the patients had not been tested for HIV at diagnosis, but only $20 \%$ of patients under age 50 , who were more likely to be HIV-positive, were untested. Only one of 105 tested women older than 70 years was HIV-positive; hence, almost all the untested older women were probably HIVnegative. However, we strongly encourage all patients to be tested prior to treatment, and since 2007 , the proportion of untested patients has declined by $50 \%$.

Another limitation is that more than $10 \%$ of patients were missing the data on grade and receptor status. Larger proportions of patients not tested than of patients tested for HIV were missing those data. Missing data is a problem in many other settings, even in more affluent countries, but one of the purposes of the database was to help the team measure up to international standards, and efforts are being made to ensure completeness of record keeping.

Although, the care we provide is comparable to that in tertiary care facilities in more affluent countries, this analysis focuses on patient presentation, not on outcomes. We believe that our patients are similar to those in other low-income urban HIV-endemic populations in Africa and that our findings are therefore generalizable. We are currently extending our database to include long-term followup of patients. Other teams of investigators elsewhere in South Africa are also developing databases so as to study HIV patterns in the setting of breast cancer. In the next few years, we hope that these data will shed light on the optimal timing of initiation of ART and chemotherapy, tolerance and toxicity of chemotherapy in conjunction with ART, and interactions between hormonal treatment for cancer and ART. Colleagues are also planning to compare the viral subtypes of HIV in breast cancer patients with those in HIV-positive controls. These efforts are essential to prepare us for the future of cancer and HIV control in high prevalence, low-resource settings.

Acknowledgments We are grateful to the patients who provided the data for this study and to the staff of the CHBAH Batho Pele breast clinic, who have served and continue to serve the patients with skill and devotion. The research described in this report was supported by the Columbia University-South Africa Training Program for Research on AIDS-related Malignancies through the National Cancer Institute, NIH (Grant \# 1D43CA153715-01). Analyses and manuscript drafting were supported by the International Agency for Research on Cancer, France.

Conflict of interest The authors declare that they have no conflict of interest.
Open Access This article is distributed under the terms of the Creative Commons Attribution Noncommercial License which permits any noncommercial use, distribution, and reproduction in any medium, provided the original author(s) and the source are credited.

\section{References}

1. Sankaranarayanan R, Swaminathan R, Lucas E (eds) (2011) Cancer survival in Africa, Asia, the Caribbean, and Central America. IARC, 305 p, ISBN 978-92-832-2162-3

2. Ferlay J, Shin HR, Bray F, Forman D, Mathers C, Parkin DM (2010) Estimates of worldwide burden of cancer in 2008: GLOBOCAN 2008. Int J Cancer 127(12):2893-2917

3. USAID: USAID HIV/AIDS Fast Facts. November 2010. http://www.unaids.org/en/dataanalysis/datatools/aidsinfo/

4. Sitas F, Pacella-Norman R, Carrara H, Patel M, Ruff P, Sur R, Jentsch U, Hale M, Rowji P, Saffer D et al (2000) The spectrum of HIV-1 related cancers in South Africa. Int J Cancer 88(3):489-492

5. Amir H, Shibata HR, Kitinya JN, Kwesigabo G (1994) HIV-1 associated Kaposi's sarcoma in an African population. Can J Oncol 4(4):302-306

6. Bernstein L, Hamilton AS (1993) The epidemiology of AIDSrelated malignancies. Curr Opin Oncol 5(5):822-830

7. Frisch M, Biggar R, Engels E, Goedert J, Group A-CMRS (2001) Association of cancer with AIDS-related immunosuppression in adults. JAMA 285(13):1736-1745

8. Herida M, Mary-Krause M, Kaphan R, Cadranel J, Poizot-Martin I, Rabaud C, Plaisance N, Tissot-Dupont H, Boue F, Lang JM et al (2003) Incidence of non-AIDS-defining cancers before and during the highly active antiretroviral therapy era in a cohort of human immunodeficiency virus-infected patients. J Clin Oncol 21(18):3447-3453

9. Goedert JJ, Schairer C, McNeel TS, Hessol NA, Rabkin CS, Engels EA, Study HACM (2006) Risk of breast, ovary, and uterine corpus cancers among 85,268 women with AIDS. Br J Cancer 95(5):642-648

10. Mbulaiteye SM, Katabira ET, Wabinga H, Parkin DM, Virgo P, Ochai R, Workneh M, Coutinho A, Engels EA (2006) Spectrum of cancers among HIV-infected persons in Africa: the Uganda AIDS-Cancer Registry Match Study. Int J Cancer 118(4): 985-990

11. Patel P, Hanson DL, Sullivan PS, Novak RM, Moorman AC, Tong TC, Holmberg SD, Brooks JT (2008) Investigators AaASoDPaHOS: incidence of types of cancer among HIVinfected persons compared with the general population in the United States, 1992-2003. Ann Intern Med 148(10):728-736

12. Shiels MS, Cole SR, Kirk GD, Poole C (2009) A meta-analysis of the incidence of non-AIDS cancers in HIV-infected individuals. J Acquir Immune Defic Syndr 52(5):611-622

13. Endo M, Inatsu A, Hashimoto K, Takamune N, Shoji S, Misumi S (2008) Human immunodeficiency virus-induced apoptosis of human breast cancer cells via CXCR4 is mediated by the viral envelope protein but does not require CD4. Curr HIV Res 6(1):34-42

14. Hessol NA, Napolitano LA, Smith D, Lie Y, Levine A, Young M, Cohen M, Minkoff H, Anastos K, D'Souza G et al (2010) HIV tropism and decreased risk of breast cancer. PLoS ONE 5(12):e14349

15. Toniolo A, Serra C, Conaldi PG, Basolo F, Falcone V, Dolei A (1995) Productive HIV-1 infection of normal human mammary epithelial cells. AIDS 9(8):859-866

16. Adebamowo CA, Famooto A, Ogundiran TO, Aniagwu T, Nkwodimmah C, Akang EE (2008) Immunohistochemical and 
molecular subtypes of breast cancer in Nigeria. Breast Cancer Res Treat 110(1):183-188

17. Anderson WF, Luo S, Chatterjee N, Rosenberg PS, Matsuno RK, Goodman MT, Hernandez BY, Reichman M, Dolled-Filhart MP, O'Regan RM et al (2009) Human epidermal growth factor receptor-2 and estrogen receptor expression, a demonstration project using the residual tissue repository of the Surveillance, Epidemiology, and End Results (SEER) program. Breast Cancer Res Treat 113(1):189-196

18. Owens MA, Horten BC, Da Silva MM (2004) HER2 amplification ratios by fluorescence in situ hybridization and correlation with immunohistochemistry in a cohort of 6556 breast cancer tissues. Clin Breast Cancer 5(1):63-69

19. Glencross D, Scott LE, Jani IV, Barnett D, Janossy G (2002) CD45-assisted PanLeucogating for accurate, cost-effective dualplatform CD4+ T-cell enumeration. Cytometry 50(2):69-77

20. Thompson ML, Myers JE, Kriebel D (1998) Prevalence odds ratio or prevalence ratio in the analysis of cross sectional data: what is to be done? Occup Environ Med 55(4):272-277
21. Barros AJ, Hirakata VN (2003) Alternatives for logistic regression in cross-sectional studies: an empirical comparison of models that directly estimate the prevalence ratio. BMC Med Res Methodol 3:21

22. Linas BS, Minkoff H, Cohen MH, Karim R, Cohan D, Wright RL, Young M, Watts DH, Golub ET (2011) Relative time to pregnancy among HIV-infected and uninfected women in the Women's Interagency HIV Study, 2002-2009. AIDS 25(5):707-711

23. Shim JS, Rao R, Beebe K, Neckers L, Han I, Nahta R, Liu JO (2012) Selective inhibition of HER2-positive breast cancer cells by the HIV protease inhibitor nelfinavir. J Natl Cancer Inst 104(20):1576-1590

24. Spano JP, Lanoy E, Mounier N, Katlama C, Costagliola D, Heard I (2012) Breast cancer among HIV infected individuals from the ONCOVIH study, in France: therapeutic implications. Eur J Cancer 48(18):3335-3341

25. Latif N, Rana F, Guthrie T (2011) Breast cancer and HIV in the era of highly active antiretroviral therapy: two case reports and review of the literature. Breast J 17(1):87-92 